\title{
A Scientific Mind Embraces Medicine: Donald Lindberg's Education and Early Career
}

\author{
Lawrence C. KINGSLAND III Ph.D. ${ }^{\mathrm{a}, 1}$ and Casimir A. KULIKOWSKI Ph.D. ${ }^{\mathrm{b}}$ \\ ${ }^{a}$ National Library of Medicine (Ret.) \\ ${ }^{b}$ Rutgers - The State University of New Jersey
}

\begin{abstract}
As a young pathologist, Donald A. B. Lindberg, M.D., tirelessly sought scientific solutions to clinical and research problems. Directing several clinical laboratories at the University of Missouri in Columbia, Dr. Lindberg developed the world's first computerized laboratory information system, speeding analysis and reporting. He directed his team in building computer systems to help clinicians retrieve medical knowledge, enable patients to find information about personal or family health issues, and provide expert automated assistance to physicians in reaching differential diagnoses outside their specialties. Developing superior functionalities with the limited information technologies of the time, Dr. Lindberg's pioneering work in Columbia foreshadowed his subsequent inspired leadership as Director of the United States National Library of Medicine.
\end{abstract}

Keywords. Donald A.B. Lindberg, Laboratory Information Systems, Computers in Medicine, Regional Medical Program, University of Missouri-Columbia, Artificial Intelligence, Knowledge Based Systems, CONSIDER, AI/RHEUM, AI/COAG.

\section{Introduction}

Donald A.B. Lindberg, M.D., enjoyed a long and distinguished life of great accomplishment, continually pushing the boundaries of medical knowledge, emerging technologies, and scientific possibilities. His education and early experiences show a curious mind seeking answers, an unflinching approach to confronting challenges, and an impressive ability to devise practical solutions to complex problems. This chapter describes aspects of Dr. Lindberg's professional development that helped lay the foundations for his visionary and innovative leadership as Director of the United States National Library of Medicine.

\footnotetext{
${ }^{1}$ Corresponding author: Lawrence C. Kingsland III, Ph.D., 50 Fox Den Road, Asheville, NC 28805 USA. E-mail: lckingsland@gmail.com
} 


\section{Brilliant Student Meets Gifted Teachers}

Donald Allan Bror Lindberg was born and raised in Brooklyn, New York. He graduated in 1950 from an excellent secondary school, Polytechnic Preparatory Country Day School on Dycker Heights. He maintained a lifelong connection with the school and would note later, "I always say - bar none - those were the most important four years of education for me" [1,p.3]. After graduating from Poly Prep and carefully researching options, Lindberg selected Amherst College for the next phase of his education. Don arrived as an English major but fell in love with biology when he met Dr. Oscar Schotté.

Dr. Schotté introduced him to experimental embryology, which Lindberg found fascinating. An Amherst honors program allowed concentration on lab experiments in the third and fourth years. The budding biologist said "We had our own labs, we had our own animals, we had our own histologists - although I could do histology" [1,p.3]. Some of his experiments with Dr. Schotté are reported in FASEB (Federation of American Societies for Experimental Biology) and in other publications [2]. Donald Lindberg graduated magna cum laude from Amherst in 1954.

The deep interest in biology led him to discuss with Dr. Schotté a doctoral program at the Rockefeller Institute, but Lindberg decided to go to medical school at the Columbia University College of Physicians and Surgeons. He would say later, "It's thrilling and it's tedious, in alternating combinations. It's a sort of a grind that's committed to large amounts of memory work, which is really almost antithetical to experimental science. But, it has its appeal. Every once in a while you get to see some patients" [1,p.4].

Donald Lindberg graduated from the College of Physicians and Surgeons (P \& S) in 1958. He had been attracted to every single medical specialty he was exposed to, one by one: internal medicine, general surgery, obstetrics, psychiatry, pediatrics, and others. He had been offered an internship in internal medicine at the College by Robert Loeb, a giant in the field. But in the end, he said, "I decided that pathology actually had answers" [1,p.4].

\section{Life-saving Discovery by a Pathology Intern}

One set of answers was particularly important. About six months into the beginning of his pathology internship, the freshly graduated Dr. Lindberg was working on analyzing causes of death at Presbyterian Hospital. Deaths from open heart surgery, then in its infancy, were quite frequent. Lindberg, working with autopsy tissues, noticed something no one had spotted before. He brought these microscopic sections to his chiefs, asking "What is this? This is a funny-looking thing." He was essentially told "Forget about it, it's nothing" [1,p.5]. But he got curious, learned about polarizing microscopes and special stains, and concluded the people were dying from the embolization of silicone particles used to reduce foaming in the oxygenators: "And so their arteries of the brain and of the heart were so choked with physical emboli that you couldn't oxygenate the tissues, and they died" [1,p.5,3].

It was late fall, halfway through the academic year. He went to the surgeons, told them what was happening, and was put off because they were too busy until perhaps 
May. Dr. Lindberg, halfway through his first year of training in pathology, notes that he "went to the Chairman of Path, a very tough character, Harry P. Smith, from Iowa... [Dr. Smith] said, 'Well, show me what you're talking about"' [1,p.5]. Lindberg did so. Dr. Smith said, "Okay, here's what you're going to do: get another dozen microscopes, set them up in the pathology library, ... I'm going to invite the Department of Surgery, and I'm starting out with the senior faculty, to have a little meeting with us" $[1, p .5]$.

The meeting took place, and speaking bluntly about a proposed follow-up meeting, H.P. Smith told the surgeons, "Either we have the meeting and you guys start doing what Lindberg wants you to do, or I'm going to call the district attorney and shut you down" [1,p.5]. Dr. Lindberg notes, "So it actually got somewhat confrontational. We did alter the surgical technique. I did do experiments with the surgeons. We did publish them in peer review journals, and everybody agreed" [1,p.5,3]. This was a remarkable accomplishment for a newly-fledged M.D. who was a pathologist-in-training halfway through his first year of residency. It is characteristic of Don Lindberg's focus and creativity in coping with an unknown tough problem, his sheer persistence and force of will, and his strong follow-through in the face of significant obstacles.

\section{Move to University of Missouri-Columbia School of Medicine}

After two years in his Pathology Residency at Columbia P \& S, Dr. Lindberg transferred to the Department of Pathology at the University of Missouri-Columbia School of Medicine. Driving around Columbia on an interview trip, Lindberg had spotted two little boys in cutoffs with bikes and fishing poles and thought "My God! What a wonderful town it must be for a kid to grow up in" [1,p.6]. He accepted the offer to move, and he and his wife Mary raised three sons in Columbia.

The Dean of the Missouri medical school was Dr. Vernon Wilson, in his first deanship. Dr. Lindberg later said "He was just an incredibly wonderful person to work with" [1,p.7]. Under Dr. Wilson, the school seemed to be moving forward quite rapidly.

As a junior faculty member, Dr. Lindberg was running several clinical laboratories and teaching pathology. He had brought with him from P \& S an NIH research grant, one of only a few at Missouri at that time. The grant combined pathology and infectious disease, investigating a Gram-negative pneumonia into which he had taken an interest. Lindberg notes, "NIH liked it enough that they gave me the money, and I brought the money to Missouri and started up a research laboratory" [1,p.7].

\section{Microbes in Orbit}

The pathologists were making ward rounds every day to see the patients with the interesting cultures. Dr. Lindberg, now a dedicated teacher in his own right, invited the pathology residents along to see and learn. Soon the internal medicine residents were coming along too. With an infected patient, and an organism cultured from the site, the immediate question is "What antibiotic should I use?" Lindberg started looking into means of assessing the sensitivity of microbes to both antibiotics and antiseptics. The 
highly-qualified young technician who was running the research lab with him was married to a gentleman named Garst Reese, a second-year physics major at Missouri who had worked for Texas Instruments for several years. Dr. Lindberg and Mr. Reese spoke about the problem, which interested both of them. Lindberg continues, "Anyway, we invented a machine. We convinced ourselves that we could get these bugs, these microbes, growing in a liquid culture, and then use Rayleigh's law to measure scatter, to get a sense of how many there were. We had a few little technical problems, like we'd have to keep them suspended, and we'd have to move them around and shine a light through it consistently, and have good photometrics" [1,p.8]. They thought in 3 or 4 months they could design this machine. It took 3 or 4 years [4]. Ultimately, NASA sent their device into earth orbit in a satellite doing environmental monitoring.

\section{World's First Computerized Laboratory Information System}

Part of this experience led Dr. Lindberg to mathematical modeling of bacterial growth patterns. Primary tasks included logging the output of the experimental device, then running a series of equations that modeled what was going on in the growth process. It became clear that something like a computer was needed. The university did have a computer center, with a Burroughs 205 paper tape machine. A card reader became available later. Lindberg concurrently oversaw the operation of several labs, such as microbiology and medical chemistry. He would later say, "So anyway, half the day I was trying to do this mathematical modeling with this old 205 and a big string of equations. The other half of the day, I was trying to get the results out of the lab... So I developed a system of a presorting, where the message would be broken up into pieces, and each of those pieces would be in a pre-punched card, and to get a message out, you'd assemble a set of these cards, and then run it through a reader. That would drive a teletype that would print a message on the ward. And then, courtesy of the university, I was assigned 15 minutes a day of computer time, which was, of course, a quarter to midnight [until] midnight" [1,p.9].

He also had an IBM 1620 by this time. That machine could read cards. He could produce a summary. Lindberg says, "I was learning more neat stuff, like the mathematics, and I was getting an improvement in the lab, and the reports were getting out not only the same day, they were getting out within minutes. Besides making the lab reports available more quickly, we had a record of them, so we could start doing some quality control, which we did right away" [1,p.10]. This was the first computerized laboratory information system in the world. It was clear to Dr. Lindberg that he needed his own computer center to do this and other systems to his own standards. Dean Wilson said, "Well, why don't you start one?" [1,p.14]. They put in an IBM 1410 using some of Lindberg's research grant funds. The university itself only had a 1401, so the two parties negotiated a certain amount of time per week for the university to use the 1410 to print thousands and thousands of salary checks. 


\section{Regional Medical Program}

Dr. Lindberg, by then doing some consulting with IBM and similar companies, saw an important missing link: contact between the university and industry, the research sides of the companies. He said he wanted his own work both to become more practical, and to benefit from more collaboration with industry. It was 1965, and the federally funded Regional Medical Programs were beginning. The genesis of these programs was President Lyndon B. Johnson's respect for Dr. Michael DeBakey, who had agreed to head a group that produced an influential report on heart disease, cancer, and stroke. Both the Regional Medical Programs and the Medical Library Assistance Act stemmed from that work.

The Regional Medical Program assumed that individual regions of the US would know best what they needed and could design their own goal-oriented projects. Program funding enabled people in a given region to conduct a needs analysis and plan corresponding projects. Lindberg said, "It had an underlying theme, from lab to bedside, so to speak. In other words, get the new discoveries out there and in use. Some of the new discoveries in those days, for instance, were myocardial infarction research and surgical intensive care units" [1,p.13].

Dean Vernon Wilson, later Vice-President of the University, was a key person in planning for regional medical programs and in advising the Washington side on writing the legislation and the appropriations correctly for the intended purposes. The net result was that Missouri received one of the first four planning grants for regional medical programs and was the first or second one actually funded. Lindberg reported, "So that solved the problem of resources and a reason to work with the engineers and the others. That was a very exciting period for me" [1,p.13]. The Missouri Regional Medical Program involved multiple individual projects; several are discussed below.

\subsection{Computer Fact Bank}

One project was the Computer Fact Bank, directed by Lawrence C. Kingsland, Jr., M.D. [5]. The Fact Bank was an open-ended collection of biomedical information equivalent to several hundred thousand text pages. It contained appropriate current facts and definitions, basic science, and clinical and research information. The majority of the collection was journal, monograph, and textbook material on $16 \mathrm{~mm}$ microfilm in cartridges and on microfiche. About 2,000 pages were in machine-readable form on magnetic tape. This information was loaded into a device called a Selectriever built by the Mosler Safe Company. Any one of these pages, whether on microfilm, microfiche, or magnetic tape, could be displayed within 30 seconds on viewing terminals from which copies of desired pages could be created if needed. Organization for retrieval was done using a Depth Index similar to a Thesaurus. The Depth Index was based on NLM's MEDLARS Subject Heading Authority Lists merged with the College of American Pathologists' Systematized Nomenclature of Pathology and the Indexes and Tables of Contents of several representative important textbooks and monographs, retaining important semantic and hierarchical relationships. 


\subsection{Remote Computer-Based EKG Interpretation}

Another Regional Medical Program project involved portable, wheeled EKG carts that recorded EKGs to reel-to-reel magnetic tape. Acoustic couplers built into the carts were used to send EKGs over telephone lines from remote locations to cardiologists for interpretation or to a new computerized system developed in Washington, D.C. by Dr. Cesar Caceres of the Public Health Service. Dr. Caceres had won awards for creating the country's first functioning computer-EKG interpretive system. He later joined George Washington University, where he was Professor of Clinical Engineering.

For most users in the late 1960s, remote access consisted of telephone lines, modems, and acoustic couplers connecting a terminal with a computer in another location. The ARPANET (Advanced Research Projects Agency Network) project began in 1966. It became the first wide-area packet-switching network with distributed control. It was also one of the earliest networks to implement the TCP/IP protocol suite. This suite allowed one network to hand off data packets to another, then another. Both technologies were critical to what we now know as the Internet. ARPANET software developers wrote applications and protocols such as Telnet and file transfer protocol (FTP). In 1971, BBN's Ray Tomlinson wrote the first email program. The ARPANET community took to it immediately. The network was declared operational in 1975 when control passed to the Defense Communications Agency [6].

\subsection{Audio Message Center}

Few households had access to a computer, but even in rural America, many had telephones. Always considering more ways to bring medical information to those with limited access to it, Donald Lindberg thought of those phones. He reasoned that offering telephone call-in to an Audio Message Center could provide an inexpensive means of playing brief audio messages on medical topics that could be helpful for patients, caregivers, and other information seekers. The low-tech but impressively effective solution he and colleague Mr. Guy Morrison came up with was a common automotive accessory of the time: an 8-track stereo cartridge tape player.

If an 8-track stereo cartridge could hold eight songs, each with a left and a right channel, then there were 16 addressable audio subchannels. Adding a little electronic surgery on the stereo playback head assembly, a few relays and other switching gadgetry, a small power supply, and a rack mountable chassis resulted in an inexpensive and quite reliable means of message playback. In quantities of 50, the tape players (bought caseless because the case would have been discarded anyway to get access to the mechanism) cost $\$ 34$ each. With 12 six-foot cabinet racks, each holding 10 cartridge tape chassis units with 16 messages per unit, the total capacity of a fully built-out system was 1,920 messages. In time, colleague Mr. Roland Ellis, who had a mellifluous voice that would have done a radio announcer proud, had recorded 1,200 messages varying in duration from 2-16 minutes. To distribute the load, these were spread across all 12 cabinet racks at 100 messages per cabinet. They were available 24 hours a day, 7 days a week, without any operator intervention. 


\section{Knowledge-Based Systems}

\subsection{Knowledge-Based Systems: CONSIDER}

The Audio Message Center and a telephone brought useful information directly to the medical consumer. Perhaps a computer could be helpful in bringing another form of useful information to the healthcare professional, such as a physician or a medical student. The CONSIDER programs developed by Dr. Lindberg and the staff of the University of Missouri Medical Center Computer Program accepted a set of signs, symptoms, or medical findings as input. They produced a differential diagnosis: a list one should consider, which might include both common, reasonable diagnoses and those of much more rare, exotic diseases or conditions. In a simple example, the student could enter two common findings, "leukocytosis" and "abdominal pain". The CONSIDER program would then respond with 29 possibilities. At the top of the list would be the two most common candidates: "pyelonephritis" and "peritonitis". The remaining 27 would include less likely, but still possible, diagnoses such as "acute intermittent porphyria" and "iliac abscess". The original CONSIDER programs were run on the IBM 1410 computer with printer and punch card outputs. Later versions on the IBM 360/50 used CDC or IBM 2260 cathode ray tube terminals for output. The organized knowledge used by CONSIDER began with the magnetic tape version of Current Medical Terminology $(C M T)$ by the American Medical Association, slightly rearranged and with a few modifications. Synonym tables were created to relate CMT diagnoses with those Standard Nomenclature of Diseases and Operations diagnoses which were used at the University of Missouri Medical Center (UMMC). It was then possible to sort the CMT tape in order of the frequency with which these diagnoses had been made at the UMMC. This way, the diseases most common at this institution would be listed first. CONSIDER was one of the first such systems in the world [7].

\subsection{SUMEX-AIM and the Rutgers Research Resource on Computers in Biomedicine}

In 1969 , Dr. Lindberg was asked by NIH to serve on a study section evaluating grant proposals in Computer Research and Biomathematics. He participated in this group from 1969 to 1971 , meeting many other pioneers in what was to become biomedical and healthcare informatics. Among them was Dr. Edward Feigenbaum of Stanford University, who became a lifelong friend. Dr. Lindberg notes, “... Ed was, even then, a real expert in artificial intelligence, and a colleague of Joshua Lederberg and Carl Djerassi and all those guys. So we kind of fell in together and started doing some projects together. That got me started in the artificial intelligence business" [1,p.15]. Dr. Lederberg was later to ask Dr. Lindberg to chair the National Advisory Committee of the NIH-sponsored Stanford Experimental Artificial Intelligence in Medicine (SUMEXAIM) project. The Committee evaluated proposals from other universities to use the computing facilities of SUMEX-AIM. Lindberg chaired this group from 1975 to 1984, during which time the existing Rutgers Research Resource on Computers in Biomedicine became the second major NIH-supported program to join with SUMEX-AIM in providing online computing resources for their work on artificial intelligence in 
medicine. These two DECsystem-20 computer complexes successfully supported university AIM research across the country for over a decade.

Dr. Lindberg at Missouri and Dr. Casimir Kulikowski of the Rutgers Research Resource on Computers in Biomedicine became close collaborators.

\subsection{Knowledge-Based Systems: AI/RHEUM}

In his travels to Stanford related to SUMEX-AIM, Donald Lindberg had met Dr. Gordon Sharp, a professor of medicine and an internationally known expert in rheumatology. Dr. Sharp subsequently was recruited to the University of Missouri to set up a Division of Immunology and Rheumatology at the School of Medicine. Deciding to explore a collaboration, Drs. Lindberg and Sharp in 1978 started a series of seminars hosted alternately by the rheumatologists and by Lindberg's computer group. The researchable problem that emerged from these seminars was the development of an artificial intelligence program that, when presented with patient findings, could suggest diagnoses in rheumatology and musculoskeletal diseases.

The system came to be called AI/RHEUM [8]. Its intended users would be physicians not having specialty training in rheumatology. Three teams were involved: Lindberg's Information Science Group and Sharp's Division of Immunology and Rheumatology at Missouri, and Kulikowski's group of computer scientists at the Rutgers Research Resource, including Sholom Weiss, who had recently completed his doctoral dissertation on the novel causal-associational network (CASNET) model of diseases. Kulikowski and Weiss had generalized CASNET into a framework called EXPERT for representing clinical expertise for the diagnosis and treatment of medical specialty diseases. EXPERT proved to be a critically important software package for helping acquire and represent the knowledge used in AI/RHEUM and subsequently in many other expert consultation programs [8]. The name was well chosen, in that EXPERT was a complex tool (or shell) for building what were coming to be called expert systems [9].

Using the EXPERT shell, the flow of reasoning for AI/RHEUM moved from its 877 potential patient findings through 467 intermediate hypotheses to eventually reach one or more of 26 potential disease conclusions. The system did not require observations for all 877 possible findings; it reasoned with whatever information was given. It notified the user if the information was insufficient to trigger any of the disease conclusions [10].

Disease criteria tables provided an information-dense means of organizing information that was both human-readable and readily translated into rules with which the EXPERT inference engine could reason. This form of knowledge representation, at the heart of AI/RHEUM, was unusual among the few medical expert systems of its time. Patient findings such as signs, symptoms, laboratory test results, or radiographic observations could be designated as Major Decision Elements or Minor Decision Elements. Other findings could be designated as Required, or as Exclusionary. Clinical combinations of those findings could lead the system to conclude that the disease in this case was Definite, Probable, or Possible [11].

Validation has been critical for clinical informatics systems under development. From its outset, AI/RHEUM was challenged using real clinical cases. As of 1986, AI/RHEUM had been tested with more than 500 carefully studied cases in three series 
[10]. Cases in the first evaluation series were selected because they carried discharge diagnoses in the system's knowledge base. AI/RHEUM diagnosed 360/384 cases correctly (94\%). The second series consisted of all but one of the cases serially admitted to the Arthritis Unit at the University of Missouri in Columbia during two 60-day periods (one chart had been lost). For those 74 cases, the researchers found that 63 carried diagnoses in the AI/RHEUM knowledge base (85\%). All 63 were correctly diagnosed. Of the 11 cases carrying diagnoses not in the knowledge base, AI/RHEUM correctly refused to make a conclusion on five. For the remaining six cases, the program was misled by features of diseases it knew, misdiagnosing all of them. The final AI/RHEUM evaluation series came from clinical rheumatologists at Keio University in Japan. They sent 59 difficult-to-diagnose cases involving patients with connective tissue diseases. AI/RHEUM diagnosed 54/59 cases correctly ( $92 \%)$, 3/59 cases partially correctly (5\%), and 2/59 cases incorrectly (3\%). Each of the cases for which AI/RHEUM was judged partially correct carried either three or four diagnoses from the Japanese rheumatologists. For each of those cases, AI/RHEUM had included all but one of those three or four diagnoses in its differential [10].

\subsection{Knowledge-Based Systems: AI/COAG}

After the AI/RHEUM system development was well under way, Dr. Lindberg in 1980 began a collaboration with another Missouri colleague, Dr. Lamont Gaston. Dr. Gaston was an expert in human hemostasis - the diagnosis and treatment of blood clotting disorders. Though clinical hemostasis problems are somewhat uncommon, they are often serious and require urgent expert attention [12]. Experts such as Dr. Gaston were both rare and sparsely distributed; most were found in large referral centers. Lindberg and colleagues hypothesized that a knowledge-based system, later called AI/COAG, could be modeled after human experts. Such a system could provide expert-level advice in locations lacking human experts. The AI/COAG system could also provide useful educational functionality for medical students, resident physicians, hematology fellows, and allied health personnel.

The original version of $\mathrm{AI} / \mathrm{COAG}$ could interpret a constellation of six laboratory coagulation screening tests and evaluate a clinical hemostasis history. The six coagulation screening tests included the platelet count, Mielke-template bleeding time, prothrombin time, activated partial thromboplastin time, thrombin time, and urea clot solubility test. While the laboratory subsystem returned a detailed analysis and interpretation of the test results, $\mathrm{AI} / \mathrm{COAG}$ was unusual in that it offered expanded information on specific aspects of the interpretation in the form of "Tell-Me-More" (TMM) items. It also provided access to the literature sources underlying the knowledge base, stored in the form of "Tell-Me-Reference" (TMR) items. Each TMM or TMR could have other TMM or TMR items embedded within it, for further detail [13].

The AI/COAG model viewed laboratory test results for each patient as a pattern. The six screening test results were viewed as a six-digit trinary number in which results are normal, decreased, or elevated. Examined in this manner, 729 six-digit patterns $\left(3^{6}\right)$ were possible. Only 324 of these were medically plausible. The full AI/COAG report for each patient's coagulation screening test results consisted of a Summary section 
reporting the test results themselves, an Analysis section that identified abnormal test results, and an Interpretation section that contained the bulk of the computer-based consultation in the form of a differential diagnostic interpretation. Embedded TMM and TMR items were available for users who might want to invoke them.

To help provide maximum guidance to the non-expert user, a final printed paragraph following the interpretation emphasized the relative prevalence of the disease entities in the differential diagnosis.

The portion of the AI/COAG system dealing with laboratory tests was used to evaluate data from 315 cases. Forty-one patterns of laboratory results were seen, with just 18 patterns comprising $90 \%$ of the cases [13]. The system suspected a hemostatic defect in 46 of the 315 cases. These were studied at an outside laboratory. Relying only on the laboratory data, $\mathrm{AI} / \mathrm{COAG}$ appropriately concluded that there was a defect of hemostasis requiring study in $76 \%$ of these cases [13].

The clinical history portion of the program was challenged to evaluate the history of 51 known patients with hemostatic defects attending the University of Missouri Medical Center. Of the 44 cases of hemophilia A or B, the system concluded that a definite hemostatic defect was present in 40 patients. For three additional patients, it concluded that a probable hemostatic defect was present. Note that from history alone, AI/COAG could conclude only that a defect was present (at the Definite, Probable, or Possible level). It did not attempt to make a specific diagnosis until laboratory test results were provided [12].

\section{New Challenges Beckon}

We have discussed only a few of the many interesting and productive projects undertaken during Don Lindberg's time at the University of Missouri. The work of Dr. Lindberg and his team there, applying science and multiple technologies to advance the knowledge and practice of medicine and biomedical research, might have continued for decades. $\mathrm{He}$ greatly enjoyed his work, and the Lindberg family loved their life in Columbia. Dr. Lindberg, however, had drawn the attention of academic and government leaders in many positions. He was urged by persons he respected to take his talents to a national and even a global stage. An important opportunity arose.

Don Lindberg left the University of Missouri in 1984 to become Director of the United States National Library of Medicine. He observed later, "NLM is great, a unique place... [P] eople are there because they can do something they can't do anywhere else" [1,p.19]. Lindberg would remain in this post for 31 years, making progress in medical science ever more available to healthcare practitioners, scientists, and the public around the world. He retired from the Library in 2015, having been instrumental in furthering multiple significant advances detailed elsewhere in this volume. 


\section{References}

[1] Ash JS, Sittig DF, interviewers. At the helm of the world's largest biomedical library: 2005 interviews of Donald A.B. Lindberg. In: Goodwin RM, Ash JS, Sittig DF, editors. Bethesda (MD): US National Library of Medicine; 2015. (Conversations with medical informatics pioneers: an oral history project).

[2] Schotté O, Lindberg DAB. Effect of xenoplastic adrenal transplants upon limb regeneration in normal and hypophysectomized newts (Triturus viridescens). Proc Soc Exp Biol Med. 1954;87(1):26-29.

[3] Lindberg DAB, Lucas FV, Sheagren J, Malm JR. Silicone embolization during clinical and experimental heart surgery employing a bubble oxygenator. Am J Pathol. 1961;39:129-144.

[4] Lindberg DA, Reese G. Automatic measurement and computer processing of bacterial growth data. Biomed Sci Instrum. 1963;1:11-20.

[5] Kingsland LC 3rd. The computer fact bank. Mo Med. 1968;65(9):734-737.

[6] https://www.britannica.com/topic/ARPANET. Retrieved March 23, 2021.

[7] Lindberg DAB. The computer and medical care. Springfield (IL): Charles C Thomas; 1968. p. 135-141.

[8] Lindberg DAB, Sharp GC, Kingsland LC 3rd, Weiss SM, Hayes SD, Ueno H, Hazelwood SE Computer based rheumatology consultant. In: Lindberg DAB, Kaihara S, editors. Medinfo 80: proceedings of the third world conference on medical informatics; 1980 Sept 29-Oct 4; Tokyo (Japan). Amsterdam (NL): North-Holland Pub. p. 1311-1315.

[9] Kulikowski CA, Weiss SM. Representation of expert knowledge for consultation: the CASNET and EXPERT projects. In: Szolovits P, editor. Artificial intelligence in medicine. Boulder (CO): Westview Press; 1984. p. 25-55.

[10] Kingsland LC 3rd, Lindberg DAB, Sharp GC. Anatomy of a knowledge-based consultant system. MD Comput. 1986 Sept/Oct;3(5):18-26.

[11] Kingsland LC 3rd, Lindberg DAB. The criteria table form of knowledge representation in medical artificial intelligence. In: Salamon R, Blum BI, Jørgensen M, editors. Medinfo 86: proceedings of the fifth world conference on medical informatics; 1986 Oct 26-30; Washington, DC (USA). Amsterdam (NL): North-Holland Pub. p. 12-16.

[12] Gaston LW, Lindberg DAB, Vanker AD, Kingsland LC. AI/COAG, a knowledge-based surrogate for human hemostasis. Mo Med. 1983;80(4):185-188.

[13] Lindberg DAB, Gaston LW, Kingsland LC 3rd, Vanker AD. AI/COAG, a knowledge-based system for consultation about human hemostasis disorders: progress report. In: Heffernan $\mathrm{H}$, editor. Proceedings of the fifth annual symposium on computer applications in medical care (SCAMC); 1981 Nov 1-4; Washington, DC (USA). Silver Spring (MD): IEEE Computer Society Press. p. 253-257. 